\title{
Evolution of the human feeding behavior
}

\author{
Fernando Sérgio Zucoloto \\ Universidade de São Paulo, Ribeirão Preto, SP, Brazil
}

\begin{abstract}
The main objective of this review is to discuss human feeding behavior based on evolution. With regard to feeding, the human species has undergone various changes during its evolutionary and social history, from the hunting and gathering phase, including the discovery of fire, to modern times, mainly after the implementation of agriculture. These changes exerted a direct influence on feeding habits and behavior and a considerable impact on some aspects of human health. The present review also discusses some of the foods consumed by the human species that are controversial among investigators from an evolutionary perspective. Keywords: human feeding behavior, evolution, controversial foods, agricultural implementation
\end{abstract}

Received 30 March 2011; received in revised form 18 May 2011; accepted 18 May 2011. Available on line 15 June 2011

\section{Introduction}

Various studies have indicated that the human species, Homo sapiens, had its origin in East Africa in the Sub-Saharan region, including the present-day Ethiopia, Libya, Kenya, and Tanzania. This might have occurred approximately 200,000 years ago. $H$. sapiens would have originated from $H$. erectus (Foley, 2003). Many people believe that human beings are not animals as defined by the word. Heated discussions occur when humans are compared with other animals. We frequently hear or read phrases such as, "Human beings, differently from the animals...," when the correct phrase should be, "Human beings, differently from other animals..." From a scientific perspective, human beings are animals, resulting from evolution and subjected to the same environmental pressures as other living beings. Although an animal species, humans possess characteristics that differentiate them from other species. One of these characteristics is the capacity to develop culture. Although other animal species have the capacity for creating, learning, and even making provisions, an enormous qualitative difference exists between them and humans. According to Tomaselo (2003), the fundamental difference between humans and other animals is language and the ability to create and accumulate culture through the ages. Cumulative cultural evolution allows our species make objects and machines that fabricate other objects and machines. This only occurs in the human species (Tomaselo, 2003).

Fernando Sérgio Zucoloto, Departamento de Biologia, FFCLRP. Correspondence regarding this article should be directed to: Fernando Sérgio Zucoloto, Av. Bandeirantes, 3900, Monte Alegre, Ribeirão Preto, SP 14040-901, Brazil. E-mail: zucoloto@ffclrp.usp.br
From the nutrition and feeding behavior perspectives, what comparisons can we make between humans and other animals? Marked differences are not apparent when humans and other animals are compared with regard to nutrition. Human nutritional needs are similar to other animals' needs (Schmidt-Nielsen, 1996). Qualitatively, nutrients in living beings are always the same, varying by one or another nutritional component. Consequently, profound changes in qualitative nutritional needs among animals are not possible, and this includes human beings. This demonstrates that the establishment of qualitative nutritional needs occurred early in the evolutionary process (Prosser \& Brown, 1968). Quantitative needs are different among living beings, depending on size, temperature, physical activity, and other factors (Zucoloto, 2008). Although the nutritional needs of humans and other animals are similar, we cannot say the same regarding behavior and feeding habits. Great differences are found in these aspects, not only between humans and other animals but also among humans. The behavior and feeding habits of nonhuman animals rarely change, unless the preferred foods are unavailable. However, great cultural influence is found regarding these aspects among humans. This influence is evident, for example, in the variety of dishes of different colonies (e.g., Arabs, Chinese, Japanese, Italian, Jewish, etc.) who live in Brazil.

Clarifying that comparative nutritional studies are possible across different species is necessary because the basic processes in this area are similar among animals, but caution must be taken when exploring feeding behavior, especially when attempting to extend conclusions from nonhuman populations to our species. Care also must be taken when these nonhuman populations are reared in the laboratory with 
artificial diets. Moreover, usually only males are used in laboratory studies. These populations also have low genetic variability, with no selective pressure among them (Zucoloto, 2008). Research that attempts to find similarities and differences in feeding behavior in different species should be encouraged when wildtype populations are used (Zucoloto, 2008).

Because the human species has always been cosmopolitan, it has established itself in and adapted itself to almost all regions of the world using local and regional foods. Based on cultural traditions, different human populations maintain their traditional feeding habits when they migrate to other regions. Additionally, our species managed to establish itself in regions where feeding is based on animal items, such as in Alaska, and vegetable items, such as in tropical locales.

\section{What is the correct diet for the human species?}

This question has challenged scientists for a long time, and the present discussions and controversies are far from resolved. In addition to scientific aspects, many other factors influence our feeding habits, such as religion, familiarity, and sociopolitics, among other factors (Milton, 1999, 2000; Friedman \& Brandon, 2001; Boaz, 2002; Cordain, 2002; Cordain et al., 2005; Zucoloto, 2008; Eaton, Konner, \& Cordain, 2010). Answering this question is not easy. Each defender of a feeding habit hypothesis has his own arguments, often based on scientific evidence but also often not. Some scientific "evidence" is very quickly changed. Soon after a pronouncement that a certain food or nutrient is good and prevents a particular disease, another team of scientists affirms the contrary. We can mention several examples. Some studies have shown that vitamin A prevents some types of cancer, whereas others maintain that it does not. Some investigators assert that vitamin $\mathrm{C}$ prevents infection, and others say the opposite. The same dichotomy can be said for soybeans and their effect on breast cancer (Santos \& Cruz, 2001; ManelaAzulay, Mandarim-de-Lacerda, Perez, Filgueira, \& Cuzzi, 2003; Rios, Antunes, \& Bianchi, 2009; Ferraz, Steluti, \& Marchioni, 2010).

To better understand the question posed above, discussing how our species' feeding habits and behaviors have evolved is necessary. Comparing human feeding behavior today and when our species emerged is also required. This will be explored below.

\section{Human habits and the evolution of feeding behavior}

When a species appears on Earth, environmental conditions must be propitious for its survival and success. According to some authors (Milton, 2000), strong evidence shows that primitive human beings were omnivorous, with a great tendency to eat many more vegetables than meat. According to others (Cordain, 2002), animals were consumed more than vegetables or at least in the same amounts as vegetables. The feeding habits of tribes that live today as huntergatherers and, consequently, in conditions similar to the Paleolithic period, include $30 \%$ products of animal origin and $70 \%$ products of vegetable origin when they live in tropical areas (e.g., the Kung), or they may feed almost exclusively on animal items if they live in very cold regions where vegetables are scarce, as the Inuits (Ungar \& Teaford, 2002; Ungar, 2007). Nonetheless, primitive humans and any other animal species should feed to meet their essential nutritional needs. Another important point is that our origin with regard to feeding habits considers humans as omnivores, permitting our species to adapt both biologically and culturally to different regions on Earth (Somer, 2001).

One of the most heated discussions about the feeding habits of primitive human populations concerns the ingested proportion of animal and vegetable items. Some authors state that vegetable items were consumed in greater proportions (Milton, 1999, 2000), whereas other authors defend the opposite (Cordain et al., 2000; Cordain, 2002). Below, we summarize the arguments of these two lines of thought.

The arguments of authors who defend the first hypothesis suggest that the human species has omnivorous feeding habits with a higher phytophagic tendency. The Savanna, which is the origin of our ancestors, is formed by arid and dry soil where seasonal fruits and bulbs are the main sources of vegetable foods, and animal sources of food are present in lower amounts. During the dry season, bulbs are used more intensely because of the scarcity of fruits. The human species is not adapted to the consumption of large amounts of animal (i.e., protein-rich) feeding sources to meet their energy needs because serious renal and hepatic problems can occur from high neoglucogenesis. Proteins are formed by amino acids that have, as their basic structure, the chemical elements carbon, hydrogen, oxygen, and nitrogen, with some exceptions, such as the insect chitin. To liberate energy, the organism uses carbohydrates and lipids. If they lack these substances, then they use amino acids. To utilize amino acids as an energy source, the organism must remove nitrogen through a process known as deamination. Thus, an amino acid molecule without nitrogen atoms can be metabolized or transformed into glucose and metabolize. In the human species, this metabolic process, known as neoglucogenesis, occurs in the liver, and the excess nitrogen must be excreted. This causes a work overload, which can seriously affect the liver and kidneys (Sackheim \& Lehman, 2001).

The defenders of the tendency of humans to be carnivores state that more than $50 \%$ of the energy used by primitive hunter-gatherers originated from 
meat. The defenders of the phytophagic tendency of humans also argue that primitive humans ingested meat and viscera that provided protein, mineral salts, and vitamins. Vegetable items, such as fruits, nuts, bulbs, and honey, would be used as energy sources and needed in higher amounts. Our species, according to these authors, is not preferentially adapted to be carnivores because it synthesizes vitamin A, which uses $\beta$-carotene as a precursor, and possesses a low capacity for neoglucogenesis. Preferential carnivores do not synthesize vitamin A, need to ingest it from animal sources, and possess a high capacity for neoglucogenesis. Regarding some hunter-gatherer tribes that preferentially feed on meat, such as the Inuits, our species' omnivorous behavior allows some populations to adapt themselves to extreme conditions by enduring higher levels of neoglucogenesis and basal metabolism, taking advantage of the vitamin A in the viscera of their prey (Ungar \& Teaford, 2002).

Another discordance among these two groups of researchers concerns human brain development. The defenders of the tendency of humans to be carnivorous hypothesize that increased meat consumption allowed for greater brain development. The other line of thought reasons that nutritionally rich items, such as nuts and chestnuts, were responsible for greater cerebral development rather than the higher consumption of meat. Moreover, fire utilization improved the nutritional value of plants, which is discussed below.

Our species' feeding habits changed after the implementation of agriculture, which is also a source of disagreement among two groups of thought. The group that asserts the carnivorous tendency argues that, after the implementation of agriculture, human populations began to consume many more vegetables than animal items, consequently leading to several degenerative diseases. The other group argues against this hypothesis, asserting that carbohydrates and refined foods were responsible for the occurrence of diseases.

From an anatomical perspective, several studies have shown that modern human beings have not changed compared with their Paleolithic ancestors. This leads us to think that our alimentation should follow the standards of that period because that was the way our species established itself on Earth (Cordain, 2002). Although the differences between these two evolutionary concepts do not affect the present discussion, recent research showed that the phytophagic tendency theory may be closer to the truth (Somer, 2001; Willet, 2002; Zucoloto, 2008; Jew, AbuMweis, \& Jones, 2009).

\section{Modifications in primitive human feeding}

The first revolution in feeding habits occurred with the "discovery" of fire by the human ancestor $H$. erectus (Rose, 2006; Wrangham, 2009). Fire must have allowed them and subsequent modern humans (e.g., $H$. sapiens) to better utilize food. Cooking favors digestion and can eliminate possible toxins contained in the food, thus probably incorporating several feeding items into the primitive human diet. Scientists hypothesize that, in addition to the feeding aspect, fire propitiated the social gathering of people for a meal. Primitive human beings must have also used fire to surround their prey during the chase and scare off predators.

The "discovery" of fire by $H$. erectus, the direct ancestor of $H$. sapiens, is not accepted by other investigators. Some assert that $H$. erectus was able to control fire and maintain it but did not create it (Mazoyer \& Rondart, 2009). Nonetheless, Wagram (2009) stated that our species has small teeth and a comparatively short digestive system. Not only $H$. erectus but also $H$. sapiens has a colon that is approximately $60 \%$ of what would be expected for the size of the body. According to this author, these adaptations would not be convenient for animals that ingest hard and fibrous roots. Moreover, cooking would transform poisonous substances possibly contained in the food into innocuous substances. $H$. erectus was the first species to use fire because it also had a relatively small digestive system, considering that it was supposedly used to ingest raw food only. Additionally, H. erectus did not climb trees and slept on the ground; therefore, fire would be useful for warding off predators (Wrangham, 2009).

The second revolution occurred approximately 11,000 years ago with the advent of agriculture in Southwest Asia. This not only signaled the introduction of grain in the human diet (e.g., oats, barley, rye, wheat, etc.) but also established the human population in certain locations. While humans were still hunter-gatherers, the populations remained in a fixed place until the moment that migrating in search of food was necessary. With the establishment of agriculture, humans no longer needed to be nomadic because food could be cultivated near their shelters. The rearing of animals also facilitated the human effort to survive in fixed locations (Diamond, 2001).

Omnivory allowed the human species to establish itself worldwide. If humans were exclusively vegetarian, then they would not establish themselves in areas with few plants, such as in Alaska. If they were exclusively carnivores, then they would have faced substantial difficulty in primitive times, mainly because successful hunting was not guaranteed (Zucoloto, 2008).

When some authors state that hunter-gatherer feeding during the Paleolithic period was more appropriate, one question arises. If humans feed themselves badly today and if human feeding before agriculture was better, then why is human longevity higher today? To answer this question, some points need to be explained.

From an evolutionary point of view, living beings must reach reproductive age and produce healthy descendants. When humans reach 13-15 years of age, 
they are ready to reproduce. Generally, this does not occur today because of nonbiological factors, including social, cultural, and financial factors. However, these aspects did not affect primitive human beings because when they reached reproductive age, they mated and produced descendants (Zucoloto, 2008).

From that period onward, the biological function of the father and mother would be to care for the offspring until adulthood and consequently until the offspring lived in conditions amenable to reproduction. The summation of the reproductive age and the time needed to care for offspring is approximately 35-50 years. Afterward, the parents no longer have any important function. From a biological perspective, why should they live beyond that time? Why would people with longer lives be selected if they do not contribute to the increase in population and still consume resources?

For human beings to reach reproductive age and care for offspring, feeding to prolong life until 70-80 years is unnecessary. Even alimentation that is not very healthy can lead humans to live until 35-40 years of age, unless other factors, such as genetic diseases, the abuse of toxic substances, and excess weight, intervene in the process.

Some scientists discuss the grandparents' role during the Paleolithic period. They suggest that they likely played a very important role in the care of their grandchildren. If we consider that the mother had to gather food and the father had to hunt, then this theory is reasonable. However, their lifespan should not have been significantly extended compared with modern human beings, considering that by the age of 40 , primitive human beings were already grandparents (Hawkes, 2003).

We cannot directly compare the longevity of hunters-gatherers with modern human populations. Instead, a comparison must be made with agricultural workers of the same time. Today, we should compare people who have habits similar to hunter-gatherers of the Inferior Paleolithic period (i.e., feeding on vegetables, fruit, lean meat, fish, and whole grains and plenty of physical exercise) with people who have different habits (i.e., feeding on fatty meats, refined carbohydrates, and few vegetables and little physical exercise). Is there any doubt who is healthier and lives longer? In these two groups, other factors must be considered, such as medical assistance, vaccinations, etc.

Comparisons between hunter-gatherer and agricultural worker populations of the same period, mainly through bone examinations, have shown that the former had higher longevity and much less degenerative and other diseases, such as anemia, osteoporosis, and reductions in the size and health of the teeth. These diseases probably appeared because of the simplification of the agricultural workers' diet that was based less on feeding items and consequently had possible nutritional deficiency (Cordain, 2002; Larsen, 2003).
A recent study administered an adapted diet similar to the Paleolithic period humans' diet and showed its superiority regarding health (Österdahl, Kocturk, Koochek, \& Wändell, 2008), even when compared with the Mediterranean diet that is today considered one of the healthiest (Lindeberg et al., 2007).

We must emphasize that the diseases caused by feeding problems appear more intensely after the age of 40 , when most couples have already had children. One may conclude that the diseases caused by poor feeding habits have their origin in environmental, nongenetic factors. However, recent research suggests that poor feeding habits can cause problems also for future generations (Kaati, Bygren, \& Edvinsson, 2002).

Critics of the Paleolithic diet state that huntergatherers did not have a high likelihood of acquiring degenerative, age-dependent diseases because they died young. However, studies with young people from industrialized societies and present-day huntergatherer societies showed that the former present high obesity indices, high blood pressure, problems utilizing insulin, which can lead to diabetes, and non-obstructive coronary atherosclerosis. These symptoms rarely occur in young individuals from hunter-gatherer societies who also present more muscle strength and higher aerobic power (Cordain, 2002).

Although hunter-gatherer societies live in quite different places, such as the tropics and the Arctic, similarities overcome differences regarding feeding habits: wild animals (low saturated fat), various vegetables that are free from chemical impurities, and abundant physical exercise. When one states that hunter-gatherers in the Paleolithic period lived much shorter lives than humans today, some points may not be taken into consideration. (1) Fossilization is influenced by various factors. If Paleolithic, fossilized bones that indicate an older age are not found, the reason could be that older bones are more difficult to fossilize because of a reduction in bone density. (2) In environments with climates similar to Paleolithic African savannas, fossilization is more difficult than in colder climates. (3) The predation of older individuals was much easier (Stringer \& Andrews, 2005). (4) Studies of the fossilized bones of different Homo species indicated a longevity potential of 82-86 years for $H$. sapiens (Helmut, 1999). Deaths during that time were mainly attributable to trauma and accidents rather than feeding problems. Today, even in marginal conditions, most hunter-gatherers reach 60-70 years of age without medical care (Goscienski, 2005).

\section{Primitive feeding vs. present-day feeding}

Our ancestors' diet was unquestionably superior to the modern diet (Cordain et al., 2005; Lindeberg et al., 2007; Zucoloto, 2008; Eaton et al., 2010). When 
we comment about today's human beings, we cannot make generalizations because in some countries or in some regions of the planet, feeding is much better than in other regions. The traditional Japanese food and socalled Mediterranean diet are examples to follow, as opposed to the fast-food diets used almost worldwide today. The traditional Japanese diet (also called the Asian diet) and the so-called Mediterranean diet are the most similar to the prehistoric human diet.

The Japanese and French ingest, with regard to both quantity and quality, many more vegetables than Americans. American feeding is based almost exclusively on four cereals: rice, potatoes, corn, and wheat, characterizing alimentation with little variation. Experiments have shown that the more we vary our feeding, the better our health because more essential nutrients and phytochemicals are ingested (Milton, 2000; Wiell, 2001; Willet, 2002; Rique, Soares, \& Meirelles, 2002; Shiva, 2003; Cordain et al., 2005; Eaton et al., 2010).

As discussed above, we can conclude that our feeding habits have substantially changed over time, but our genome has stayed relatively the same concerning metabolism- lactose and gluten tolerance, as well as several hemolytic anemias, are possible exceptions(Cordain et al., 2000). According to some authors, several diseases found in our populations today are generated by the contrast between a genome selected for a particular type of diet and lifestyle and the diet and lifestyle changes that have occurred throughout our evolutionary history (Milton, 1999, 2000; Cordain, 2002). Below we discuss some of these aspects.

\section{Feeding alterations and modern diseases}

Apparently, investigators agree that alterations in feeding habits throughout time influence the appearance of diseases in humans. Disease frequency and kind depend on feeding habits in each region of Earth (Jew et al., 2009). Several studies and opinions have associated poor feeding habits with different types of cancer, hypertension, and cerebral vascular disease, but others have not confirmed these associations. Type II diabetes is undoubtedly related to changes in feeding habits and a sedentary lifestyle (Cordain, 2002; Cordain et al, 2005). Type II diabetes, also known as insulin-independent diabetes, also appears to have a very strong relationship with obesity. Obesity causes a low utilization of insulin and creates cellular resistance. Consequently, glucose is not adequately utilized, resulting in diabetes and its consequences (Wiell, 2001; Puppin, 2002; Willet, 2002). Although the primary cause of obesity is easily understood (i.e., obesity occurs because of an excessive ingestion of calories), explanations from an evolutionary point of view have caused several controversies.

The discussion may begin by mentioning the appearance of the economic gene theory in the early 1960s. Before agriculture, our ancestors lived by hunting and gathering on the African continent and afterward in other parts of the world. This kind of subsistence did not guarantee feeding stability for primitive humans. They would go through cycles of abundance and starvation. Likely by natural selection, the economic gene carriers had a better probability of survival. During an abundance cycle, the economic gene would induce the primitive humans to ingest more food than was actually necessary. The surplus calories would be stored and used in times of food scarcity. Today, with no food scarcity and a genome that has altered little, the economic gene would continue to be active. This condition may ally with a lack of physical exercise and an excessive ingestion of calories to generate obesity (Neel, 1962).

Numerous criticisms have appeared regarding the economic gene theory, most of which consider it too simplistic. A more logical consideration may be that several genes are active, according to lipostatic theory, modulating appetite and being differentially selected, depending on the region and food distribution and frequency (i.e., more vegetable sources or more animal sources). Concerning economic gene theory, lipostatic theory defenders question how an overweight human would run away from predators (Speakman, 2006; Zucoloto, 2008). Is not being overweight harmful to one's health?

The economic gene theory supported by some today has never clarified, not even hypothetically, how long each cycle would last. Having metabolic mechanisms that reserve calories could have enabled the primitive human population to utilize these calories during the day while hunting or gathering.

The caloric reserves would not be large enough to be used during a long period of food scarcity for a series of reasons. One of the reasons, mentioned above, is related to being overweight, which is harmful to one's health. Another fact is that human metabolism is not adapted to metabolize fats over a long period of time because of the risk of ketosis. Ketosis is a metabolic condition in which ketone bodies increase in the blood as a consequence of the metabolism of fats, affecting the action of red blood cells and consequently breathing. In some cases, ketosis can cause death.

Human brain metabolism works basically with glucose. A lack of this substance for prolonged periods of time can cause serious problems in the brain. In threshold conditions of carbohydrate deficiency, glucose synthesis can occur using lipid sources, but if that situation persists, it can damage health. Metabolic adaptations in the human species may support the above discussion. While walking, 55\% of the energy expended is derived from fatty acids (lipid components), and the rest is derived from carbohydrates. While running, only $35 \%$ of the energy expended is derived from fatty acids (Matsudo, Matsudo, Araújo, \& Ribeiro, 2005). During the Paleolithic period, humans only ran in situations of stress. The remainder of the time, they walked with 
more or less intensity depending on the situation. This demonstrates the following adaptation. Glucose would be reserved for the brain and emergency situations. With the different uses of fatty acids and glucose, depending on the situation, the risk of ketosis would be absent, and a glucose reserve would exist for emergency situations because of faster metabolism (Zucoloto, 2008). With more intense physical exercise, such as running, the individual becomes hungrier. This fact shows that with intense physical exercise, carbohydrate depletion may occur in the organism, increasing the sensation of hunger. A possible explanation for this is hormonal control, but our species must also have carbohydrate reserves, which would explain the sensation of hunger after intense physical exercise and is fundamental in emergency situations. Notably, one of the physiochemical characteristics of carbohydrates, in contrast to lipids, is the strong attraction for water. This demands a large amount of this liquid in cases in which nutrients are used in high quantities as an energy reserve. Additionally, each gram of lipid provides nine calories, whereas the same amount of carbohydrates provides four calories (Sanders \& Emery, 2003).

The hypothesis that the human species as huntergatherers was subject to unpredictable resources and the constant threat of starvation is based on research conducted with populations that lived in marginal areas in the early 20th century. These marginal areas did not have abundant feeding resources during this time. However, this was not the case with the first human populations of hunter-gatherers, in which they lived in areas where food was always available and sufficient (Somer, 2001; Moran, 2000). Hunter-gatherer feeding was constant and varied in the savannas where H. sapiens originated (Goscienski, 2005). Starvation periods only appeared after the implementation of agriculture. Hunter-gatherers had abundant food and the ability to move and find food easily (Cordain, Miller, \& Mann, 1999; Prentice, 2005).

Moreover, if the hypothesis that fire was used by the human species since the beginning of its existence, the possibility of food scarcity, even for short periods, would be highly improbable. Cooking would make any available food easily digested with no toxins (Rose, 2006; Wrangham, 2009).

Specialists have proposed other theories to explain the occurrence of obesity, based on the evolutionary discussion. Food shortage has only appeared with the implementation of agriculture. In the primitive human species who lived as hunter-gatherers or today's huntergatherer societies, no paleontological evidence of food scarcity has been found. Periods during which these populations fed themselves with less than was necessary have been short (i.e., a few days, if so). How can a species establish itself in an environment where food scarcity can occur without metabolic adaptations that overcome the situation? How could the species develop a so-called efficient brain by depending so much on daily energy derived from glucose? See Prentice (2005) and Zucoloto (2008) for a discussion.

After the implementation of agriculture, the human populations began to consume few feeding items, in contrast to hunter-gatherer societies. An unforeseen occurrence with one of those feeding items could mean food scarcity. Additionally, with the population growth caused by agriculture, people became sedentary. With lower nutritional value, the production of food would be sufficient to maintain more people (Cordain, 2002; Prentice, 2005).

Although chronic food shortages can occur because of the problems caused by agriculture, we must also discuss what might have happened when the human populations began to migrate from Africa to other regions before the implementation of agriculture. When the human populations migrated from Africa to other locations, feeding moved away from ancestral standards. In the Inuits, for example, osteoporosis was caused by increased acidity attributable to alterations in Paleolithic hunter-gatherer feeding (Eaton et al., 2010).

Depending on the region to where they migrated, the human populations could suffer more or less food scarcity, mainly in colder regions or where some factors did not allow feeding source stability. From an evolutionary point of view, two situations could arise. First, genetic selection may have favored people who had more physiological ability to reserve calories. Second, physiological changes may have altered metabolism, depending on higher or lower feeding availability. These alterations could occur without genetic changes in a process called phenotypic plasticity. In this process, with no genetic alterations, the organism can adapt to different environmental situations (Jablonka \& Lamb, 2009). Today, we must consider the epigenetic effects on feeding and metabolic processes. Epigenetics can be defined as a process in which genes can be activated or deactivated in a new environmental situation, enabling the organism to better perform without modification of the genome. Evidence indicates that this process can be passed to future generations. That is, the genes are activated or deactivated in a generation and transmitted to the following generation (Heijmans et al., 2008; Lopez-Jaramillo et al., 2008; Choi \& Friso, 2009; Jablonka \& Lamb, 2009, Eaton et al., 2010).

The human species appeared in Oriental Africa. Even inside Africa, however, the populations may have migrated to other regions, altering the feeding items in their diets (Olson, 2003). The most recent research on human feeding behavior and the mechanisms that regulate hunger and satiety reveal a much more complex picture with both common and different mechanisms, depending on the region from which the individual originated (Zucoloto, 2008). Some studies and clinical observations indicate that the aforementioned 
hypotheses are plausible. Genetic factors, phenotypic plasticity, and epigenetics may involve mechanisms that regulate food ingestion, hunger, and satiation. Below are two examples.

Research has shown that when men and women are fed the same amount of calories during the day but in two different ways, the results are different. If the meals are provided three times per day at large intervals, then they accumulate fat in higher amounts than when the meals are provided six times a day at shorter intervals. These results suggest that the organism metabolically adapts itself, depending on the availability of food (Blundell, Burkey, Cotton, \& Lawton, 1993; Metzner, Lamphiear, Wheeler, \& Larkin, 1997). One plausible explanation for this is that when the organism receives nutrients in higher amounts at longer intervals, metabolism acts by storing as many calories as possible, and these calories are used to release energy during the intervals when no food is available. In contrast, when the organism receives nutrients in lower amounts but at shorter intervals, metabolism acts by storing fewer calories. Paleolithic hunter-gatherers may have fed themselves as such, with the exception of situations of very successful hunting. If this theory is confirmed, then a mechanism must control the metabolic rate of the organism by sometimes increasing and sometimes decreasing it.

Other results showed that the number of adipocytes (i.e., cells responsible for storing fat) is genetically determined. However, if during the growth phase the individual ingests more food than necessary in such a way that the organism's adipocyte capacity is exhausted, then this number can increase proportionately with the ingestion excess. This may explain why the individual who reaches adulthood while overweight (and with adipocytes in excess of that acquired during the growth phase) has more difficulty resuming a normal weight than an individual who became overweight during adulthood. Therefore, by reaching adulthood with a normal weight, the number of adipocytes limits the excess of stored calories (Soares \& Petroski, 2003).

In summary, human beings that lived in the African savannas maintained their normal weights because of the constant availability of food and intense physical activity. Metabolic mechanisms would of course allow caloric reserves, but these reserves would not surpass normal limits. Because evolution cannot see into the future, when humans expanded to other regions on Earth and their way of life was modified by a reduction of physical activity and the ingestion of unhealthy foods, problems began to appear.

Comparative research has shown that the health of hunter-gatherer societies was much better than that of the first agricultural workers. Perhaps the most important explanation for these differences is a reduction of the alimentary diversity of the populations who began to subsist from agriculture. The smaller our feeding menu, the greater our chances of having nutritional deficiency and consequently acquiring diseases. Another reason for these differences could be that primitive agricultural workers based their feeding on grains, which are known to have a poor phytochemical content.

Some authors have stated that diseases appeared because primitive agricultural workers reduced their ingestion of meat and increased their ingestion of grains, a situation for which our metabolism was not prepared (Cordain, 2002). Other authors disagree and assert that diseases appear when the ingestion of refined foods increase to the detriment of whole grain ingestion (Milton, 1999, 2000). Fundamental changes have occurred in the feeding habits and lifestyle of humans over time. These changes fundamentally caused the so-called "civilization diseases" to appear (Cordain et al., 2005).

Our genome was "molded" in an environment with feeding source variety, intense physical exercise (people walked approximately $12 \mathrm{~km}$ per day), and small populations. Food did not contain chemical poisons and was not refined. Today, vegetables are cultivated using chemical poisons, and meat has a high proportion of saturated fat. A great part of the population does not engage in physical exercise, and the population has grown uncontrollably. Therefore, the life that much of the human population enjoys today does not reflect the lifestyle for which it was selected from an alimentary and metabolic point of view (Zucoloto, 2008).

The way to a healthy life with regard to feeding behavior and physical activity seems clear by following the model of our antecestors. Living in caves, as some might say, and hunting or gathering our own food are unnecessary. Our species was "molded" during its evolution and adapted to the conditions at the time, without exaggerated extremes.

Grains and whole cereals, vegetables, fruit, and lean meat (i.e., mainly poultry and fish) must be the basis of healthy feeding. Whenever possible, eat organic food, practice physical exercise, and drink healthy liquids such as water and fresh juices. Research shows that the proportion of vegetables and animal items consumed daily should be 3:1 (Milton, 1999, 2000). The amount of ingested food must meet our basic nutritional needs and be directly related to our physical activity so we do not lack or have excessive calories.

Two points must be clarified. First, the cultivation of organic foods must be performed by obeying agroecological principles and avoiding monocultures. According to this principle, chemical poisons and hormones are not utilized and a connection exists between biotic and abiotic factors with animal and plant diversity. Second, when one argues that healthy alimentation is inaccessible to lower income classes, we must remember that this argument must be supported by profound social reform because it is a political and not a scientific issue (Zucoloto, 2008). 
To conclude this review, form an evolutionary perspective, some foods that have generated much controversy regarding their harmful and beneficial effects are discussed.

\section{Controversial foods and evolution}

Below are discussed foods that have generated controversies in the scientific literature and can be analyzed from an evolutionary point of view (Ritchie, 1995; Counihan \& Van Esterik, 1997; Diamond, 2001; Larsen, 2003; Fernández-Armesto, 2004; Zucoloto, 2008; Aronne \& Bowman, 2009; Eaton et al., 2010).

Milk

The main argument that the defenders of the noningestion of milk make is that human beings, among the mammals, are the only species that uses milk as a food in adulthood. No other mammal drinks milk, with the exception of pets (e.g., cats and dogs) when the owners offer it. They also argue that if nature "wanted" the humans to continue to drink milk after weaning, then the mothers would continue to produce it. Humans only drink milk after weaning because they have domesticated animals that produce it, such as cows and goats. Nevertheless, they claim that the milk of these animals has a very different composition from human milk. Those who defend the use of milk by the human species after weaning say that it is a very nutritional food that is rich in calcium and protein and is useful for the prevention of osteoporosis in the elderly, primarily women.

Humans only began to ingest milk after weaning when they eventually domesticated animals. How could humans 11,000 years ago obtain the calcium and protein that are so abundant in milk? Investigators calculated that humans began to drink non-maternal milk approximately 5500-6000 years ago. The answer contains elements that will be used in several other discussions about the feeding habits of humans.

Studies have shown that primitive human feeding had much more calcium than in the current alimentation of middle-class North-Americans. Protein was obtained by ingesting meat from different origins, eggs, and chestnuts. Calcium could be obtained from meat, fish, and sometimes vegetable sources.

Research has revealed two very important points. During the Paleolithic period, human feeding was much more varied, and the foods were richer in certain nutrients. After the implementation of agriculture and during the periods that followed until today, humans selected the foods to be used in their feeding by giving more preference to production than nutrition. The Paleolithic hunter-gatherers, because food diversity was great, managed to balance their diet without including milk. Today, with much less varied feeding caused by cultural and economic factors, humans have been forced to rely on foods that evolution did not "prepare" them to use or nutrients in the form of pills.

Is milk ingestion after weaning detrimental to health? The arguments presented in this review inform us that humans do not need milk after weaning. Nonetheless, from a health perspective, would that prevent humans from drinking milk? If the answer is yes, then what is the evidence? Approximately $75 \%$ of the adults in the world are unable to digest the milk sugar called lactose. These people, as adults, do not have the enzyme lactase that is always present in breastfeeding children and necessary for lactose digestion. If these people ingest milk, then they may experience colic or dysentery. Most people who maintain lactase until adulthood live in or come from very cold regions where milk-producing animals are reared, such as in northern Europe. Because vegetables have always been scarce in these regions, feeding based on milk and meat has been the solution. Genetic selection may have favored people who maintain lactase into adulthood. Those who do not have lactase use curded milk. Curded milk has the same composition as milk, but the lactose is decomposed by the action of bacteria. Therefore, people who do not have lactase can ingest curded milk (e.g., in the form of yogurt) without digestion problems.

People who ingest milk products may also suffer allergic reactions, including migraine, in response to the proteins present in this food. According to some investigators, this could represent evidence that adult humans are not physiologically prepared to consume milk and its products.

The ingestion of whole milk can increase the levels of some substances that are harmful to health, mainly affecting the heart and circulation. Whole milk and its derivatives are rich in certain types of lipids and cholesterol (see discussion below) that, in excess, can be problematic to human health. In the market, we can find milk that lacks lipids, referred to as fat-free milk.

\section{Meat}

The discussion of meat can become heated, with biological, medical, and religious aspects. From the religious perspective, some argue that animals must not be killed by humans to be used as food. They also allege that animals can eat each other because, in contrast to humans, they do not have a soul and cannot understand divine creation. These arguments classify humans as nonanimals, which contrasts with the biological perspective.

Meat, independent of its origin, is impregnated by hormones used to accelerate the animal growth process and antibiotics used to avoid infections. Both the hormones and antibiotics ingested in the meat by human beings can trigger several health problems. Several defenders of the non-ingestion of meat argue that the precocious menarche (i.e., first menstruation) of adolescents today results from the high consumption 
of meat that contains hormones. In addition to this argument, which holds for meat from any source, with the exception of organic meat, two additional arguments state that red meat should not be consumed. Excessive lipids are harmful to health, in addition to the excessive toxic substances released during animal processing. Generally, red meat from cattle has more intense metabolism than so-called white meat from poultry and fish. More toxic substances accumulate as a result of increased metabolic activity. The red color is caused by a higher concentration of hemoglobin, the respiratory pigment that appears more intensely in tissues with a higher metabolic rate. Human beings in the huntergatherer phase ingested little meat, and the human digestive apparatus is more adapted to omnivorous feeding, tending to ingest more vegetables than animal products. Those who favor meat ingestion partially agree with these arguments. They think that humans must ingest meat but in moderation. They assert that many people consume to much meat, resulting in health problems. Meat is a rich source of protein and iron, in addition to vitamin B12 which is not found in plants. These nutrients, with the exception of vitamin B12, can be found in other foods, including milk products.

If vitamin B12 is essential for health and found only in animal products, and Paleolithic humans did not have milk at their disposal after weaning, where did they obtain that vitamin if not from meat and eggs? We know that the main sources of vitamin B12 are cattle viscera (liver and kidney), meat, milk, and eggs. The amount found in milk and eggs is much less than that found in viscera and meat. In the liver, the range is from 30 to $120 \mu \mathrm{g}$. In the kidneys, the range is from 18 to $55 \mu \mathrm{g}$. In milk and eggs, the range is from 0.3 to $0.4 \mu \mathrm{g}$. These amounts are contained in $100 \mathrm{~g}$ of food. According to the literature, humans need approximately 2 to $4 \mu \mathrm{g}$ of vitamin B12 daily. Because milk was not available to adult humans during the Paleolithic period, the equivalent of approximately 10 chicken eggs would need to be eaten to meet the daily vitamin B12 needs. Otherwise, the ingestion of viscera and meat would be necessary. Each individual would need to obtain 10 eggs per day from nests. This would be a difficult task if we consider the constant protection of the nests by the parents. Additionally, would the digestive system tolerate such a massive daily consumption of eggs? Although the aforementioned values can vary, the differences among feeding sources are considerable. These data were derived from recent research, but we do not know whether the needs were greater during the Paleolithic period. Vitamin B12 plays a role in the maturation of blood cells, directly influencing metabolism. Notably, energy expenditure during that time was much higher than today.

In conclusion, strong arguments defend the ingestion of meat by the human species. Several vegetarians say that finding vitamin B12 in plants is possible. Other authors do not agree. We do not know and may never know whether prehistoric vegetable foods contained vitamin B12. The bacteria present in soil synthesize vitamin $\mathrm{B} 12$, and animals that ingest these bacteria with food would be the vitamin source. In ruminants, such as cattle, the bacteria present in the digestive apparatus synthesize vitamin B12, which will be used by these and other animals that eat their meat, including human beings.

What has research shown about the ingestion or noningestion of meat by primitive human beings? Prehistoric human beings ingested meat. The amount consumed depended on the region, the time period, and the hunting conditions. In cold climates with little vegetable availability, humans may have greatly depended on meat. Several investigators assert that the chasing of prey greatly influenced the socialization of the human species and the development of language and speech.

Understanding the marked differences between the Paleolithic period and today is necessary. One of the most important differences concerns the composition of meat. The several types of meat we ingest today are derived from domesticated, confined animals fed concentrated diets. These conditions confer a much higher concentration of lipids in the meat compared with the meat from wild animals, which were the meat source for Paleolithic humans. Recent research demonstrated less than a $4 \%$ lipid content in wild animal meat and a $25-30 \%$ lipid content in domesticated animal meat. Additionally, wild animals have in their lean tissues (muscles) high concentrations of unsaturated fatty acids, which are beneficial for health, in contrast to confined animals that have high concentrations of saturated fatty acids, which are harmful.

How do people who live in cold regions, such as the Inuits and Eskimos, and feed primarily on meat have healthy lives by ingesting high amounts of saturated fatty acids and cholesterol? Although cholesterol is considered detrimental to human health, we must remember that it is important for sexual hormone (e.g., estrogen, testosterone) and cortisone synthesis, in addition to its role in the cell membrane. It is also important in vitamin $\mathrm{D}$ synthesis.

The Inuits' feeding is rich in omega 3, which protects arteries from platelet agglutinate-forming clots and hindering normal blood circulation. This substance is the precursor for the synthesis of prostaglandin, which is important for growth, cell differentiation, and immune responses and a structural part of cerebral cells. Consequently, omega 3 is important for both physical and mental health.

Among the unsaturated fatty acids are two that are essential for human health. We need them but do not synthesize them and must ingest them in food. These two acids are linoleic acid and linolenic acid. Because of its chemical structure, linolenic acid is an omega 3, and linoleic acid is an omega 6 . These two fatty acids must 
be balanced in our organism. Omega 6 is abundantly found in food, including pork, seeds, nuts, and vegetable oils. Omega 3 is not as abundant and found in sardines, salmon, flax oil, some nuts, and chestnuts, which are highly consumed by the Inuits but not by the general population. Several authors have reported that several modern diseases are caused by the low ingestion of linolenic acid. Paleolithic hunter-gatherers consumed omega 3 by ingesting meat from mammals and birds that fed on grasses rich in omega 3.

In addition to the quantitative aspects, we must also mention that prehistoric animals, which served as food for human beings, fed on vegetable items rich in phytochemicals. Today, the animals that humans use as food are treated with feeds that do not contain such substances. If primitive human beings ingested meat, and that was the only available source of vitamin B12, then this means that we must ingest meat, although in a much lower amount than we ingest it today.

\section{Sugar}

Another important point to discuss concerns the human consumption of sugar. Sugars and starch are carbohydrates. The main difference between the sugars, including sucrose, the common sugar used to make sweets, cakes, etc., and starches found in cereals, leaves and used to make cookies is that starch molecules are larger than sugar molecules. The starch consumed by primitive humans was contained in whole foods rich in several other nutrients and consequently more nutritional. Modern humans ingest much more sugar than their ancestors. Studies have shown that excessive sugar ingestion may seriously compromise the teeth, in addition to causing obesity and type II diabetes. Primitive humans ingested sugar contained in occasional foods, such as fruit. Higher carbohydrate sources were found in roots, which lack sugar but are rich in starch and fiber.

In addition, recent studies have shown that the carbohydrates contained in whole foods are healthier than the refined carbohydrates added to sweets, cakes, ice cream, and cookies.

Carbohydrates (i.e., polysaccharides, such as starch) were considered healthy, and monosaccharides and disaccharides (i.e., sugars) were considered unhealthy. Today, these concepts have changed because of discoveries that allowed the introduction of the terms glycemic index and glycemic load in the scientific literature. The glycemic index is the amount of glucose released within a certain period of time after foods that contain carbohydrates are ingested. To determine the glycemic index, $50 \mathrm{~g}$ of the carbohydrate contained in the food are administered. This amount is compared with a standard that may be sucrose or white bread. An arbitrary value (e.g., $100 \mathrm{~g}$ for sucrose and $130 \mathrm{~g}$ for white bread) is assigned, and a comparison is made with the food being tested. For example, potatoes, which are rich in starch, have a glycemic index similar to sucrose and higher than fructose, which is the sugar contained in fruit. Glycemic load is the carbohydrate content in food multiplied by the glycemic index. The glycemic load concept provides a better idea about the effects of ingesting a certain source of carbohydrates. Carrots, for example, have a glycemic index of 131, which is higher than the glycemic index of 100 of pure sucrose. However, the carbohydrate content of carrots is low, approximately $8 \%$. This indicates that to attain a glycemic index of 131, we must ingest approximately $600 \mathrm{~g}$ of carrots. The consequence of having a high glycemic index and high glycemic load is excess insulin released in the blood, causing serious damage to the arteries and favoring lipid accumulation, obesity, and diabetes. The factors that affect the glycemic index and glycemic load are refined or whole carbohydrates and composition. The refined food glycemic index is higher than the whole grain glycemic index.

Recent research showed that foods made with refined carbohydrates rich in sugar and fat promote resistance to satiation because they interfere with the messages sent to the brain that normally signal the animal to cease food ingestion. Our hypothesis regarding this issue is that our physiological system was selected by feeding on whole foods with limited amounts of sugars and fat. The food satiation signal is logically linked to the ingestion of whole foods that have little sugar and fat, similar to the Paleolithic period.

If sugars and saturated fat, when ingested in high amounts, are harmful to our health, then why do we like them so much? Why did evolution not prepare us to not ingest great amounts of the foods that contain them? Foods that contain sugar (mainly fruits) and fats (basically meat, nuts, and chestnuts) were not available all of the time for primitive human beings. Fruits were seasonal, and meat depended on hunting success, in addition to having a chemical composition that was different from the meat consumed today. We may conclude that these nutrients are necessary in low amounts and that primitive humans possessed a very efficient mechanism to perceive them because they were not easy to find. Because the mechanisms of perception did not change during human evolution, imagining the pleasure we feel when we eat foods rich in sugar and fat is easy.

\section{General conclusion}

Knowing the diverse theories of feeding, if we want to institute healthy alimentation, then we must direct our attention to the feeding behavior of our species during the Paleolithic hunter-gatherer phase and make appropriate changes. Advice aimed at a healthy life points in the direction of Paleolithic human feeding and physical activity, which was the usual custom of our ancestors. 


\section{References}

Aronne, L.J., \& Bowman, A. (2009). The skinny: on losing weight without being hungry. New York: Broadway Books.

Blundell, J.E., Burkey, V.J., Cotton, J.R., \& Lawton, C.L. (1993). Dietary fat and the control of energy intake: evaluating the effects of fat on meal size and postmeal satiety. American Journal of Clinical Nutrition, 57(5 Suppl), 772S-778S.

Boaz, N. (2002). Evolving Health. New York: John Wiley and Sons.

Choi, S.W., \& Friso, S. (2009). Nutrients and epigenetics. Boca Raton: CRC Press.

Cordain, L. (2002). The paleo diet: lose weight and get healthy by eating the food you were designed to eat. New York: Wiley.

Cordain, L., Miller, J., \& Mann, N. (1999). Scant evidence of periodic starvation among hunter-gatherers. Diabetologia, 42, 383-384.

Cordain, L., Miller, J.B., Eaton, S.B., Mann, N., Holt, S.H.A., \& Speth, J.D. (2000). Plant-animal subsistence ratios and macronutrient energy estimations in worldwide hunter-gatherer diets. American Journal of Clinical Nutrition, 71, 682-692.

Cordain, L., Eaton, S.B., Sebastian, A., Mann, N., Lindeberg, S., Watkins, B.A., O'Keefe, J.H., \& Brand-Miller, J. (2005). Origins and evolution of the Western diet: health implications for the 21 st century. American Journal of Clinical Nutrition, 81, 341-354.

Counihan, C., \& Van Esterik, P. (1997). Food and culture: a reader. New York: Routledge.

Diamond, J. (2001). Armas, germes e aço. Rio de Janeiro: Record.

Eaton, S.B., Konner, M.J., \& Cordain, L. (2010). Diet-dependent acid load, Paleolithic nutrition, and evolutionary health promotion. American Journal of Clinical Nutrition, 91, 295-297.

Fernández-Armesto, F. (2004). Comida, uma história. Rio de Janeiro: Record.

Ferraz, C.M., Steluti, J., \& Marchioni, D.M. (2010). As vitaminas e minerais relacionados à estabilidade genômica e à proteção ao câncer. Nutrire, 35(2), 181-199.

Foley, R. (2003). Os humanos antes da humanidade. São Paulo: UNESP.

Friedman, M., \& Brandon, D.L. (2001). Nutritional and Health Benefits of Soy Proteins. Journal of Agricultural and Food Chemistry, 49, 1069-1086.

Goscienski, P.J. (2005). Health secrets of the stone age: what we can learn from deep in prehistory to become leaner, livelier and longerlived, (2nd edition). Oceanside: Better Life.

Hawkes, K. (2003). Grandmothers and the evolution of human longevity. American Journal of Human Biology, 15, 380-400.

Helmut, H. (1999). The maximum lifespan potential of Hominidae: a re-evaluation. Homo, 50, 283-296.

Heijmans, B.T., Tobi, E.W., Stein, A.D., Putter, H., Blauw, G.J., Susser, E.S., Slagboom, P.E., \& Lumey, L.H. (2008). Persistent epigenetic differences associated with prenatal exposure to famine in humans. Proceedings of the National Academy of Sciences of the United States of America, 105, 17046-17049.

Jablonka, E., \& Lamb, M.J. (2009). Evolução em quatro dimensões. São Paulo: Companhia das Letras.

Jew, S., AbuMweis, S.S., \& Jones, P.J.H. (2009). Evolution of the human diet: linking our ancestral diet to modern functional food as a means of chronic disease prevention. Journal of Medicinal Food, 12, 925-934.

Kaati, G., Bygren, L.O., \& Edvinsson, S. (2002). Cardiovascular and diabetes mortality determined by nutrition during parents' and grandparents' slow growth period. European Journal of Human Genetics, 10, 682-688

Larsen, C.S. (2003). Animal source foods and human health during evolution. Journal of Nutrition, 133(11 Suppl. 2), 3893S-3897S.

Lindeberg, S., Jönsson, T., Granfeldt, Y., Borgstrand, E., Soffman, J., Sjöström, K., \& Ahren, B. (2007). A Paleolithic diet improves glucose tolerance more than a Mediterranean-like diet individuals with ischaemic heart disease. Diabetologia, 50, 1795-1807.

Lopez-Jaramillo, P., Silva, S.Y., Rodrigues-Salamanca, N., Duràn, A., Mosquera, W., \& Castillo, V. (2008). Are nutrition-induced epigenetic changes the link between socioieconomic pathology and cardiovascular diseases? American Journal of Therapeutics, 15, 362-372.

Manela-Azulay, M., Mandarim-de-Lacerda, C.A., Perez, M.A., Filgueira, A.L., \& Cuzzi, T. (2003). Vitamina C. Anais Brasileiros de Dermatologia, 78(3), 1-10.

Matsudo, V.K.R., Matsudo, S.M.M., Araújo, T.L., \& Ribeiro, M.A. (2005). Dislipidemias e a promoção da atividade física: uma revisão na perspectiva de mensagens de inclusão. Revista Brasileira de Ciência e Movimento, 13, 161-170.

Mazoyer, M., \& Rondart, L. (2009). História dos agricultores no mundo. São Paulo: UNESP.

Metzner, H.L., Lamphiear, D.E., Wheeler, N.C., \& Larkin, F.A. (1997). The relationship between frequency of eating and adiposity in adult men and women in the Tecumseh Community Health Study. American Journal of Clinical Nutrition, 30, 712-715.

Milton, K. (1999). A hypothesis to explain the role of meat-eating in human evolution. Evolutionary Anthropology, 8, 11-21.

Milton, K. (2000). Hunter-gatherer diets: a different perspective. American Journal of Clinical Nutrition, 71, 665-667.

Moran, E.F. (2000). Human adaptability: an introduction to ecological anthropology. Boulder: Westview Press.

Neel, J.V. (1962). Diabetes mellitus: a "thrifty" genotype rendered detrimental by "progress"? American Journal of Human Genetics, $14,353-362$.

Olson, S. (2003). A história da humanidade. Rio de Janeiro: Campus.

Österdahl, M., Kocturk, T., Koochek, A., \& Wändell, P.E. (2008). Effects of a short-term intervention with a paleolithic diet in healthy volunteers. European Journal of Clinical Nutrition, 62, 682-685.

Prentice, A.M. (2005). Starvation in humans: evolutionary background and contemporary implications. Mechanisms of Ageing and Development, 126, 976-981.

Prosser, C.L., \& Brown, F.A. (1968). Fisiologia comparada (2nd edition). México City: Interamericana.

Puppin, S. (2002). Doenças cardiovasculares. Rio de Janeiro: Editora Rio.

Rios, A.O., Antunes, L.M.G., \& Bianchi, M.L.P. (2009). Proteção de carotenóides contra radicais livres gerados no tratamento de câncer com cisplatina. Alimentação e Nutrição, 20, 343-350.

Rique, A.B.R., Soares, E.A., \& Meirelles, C.M. (2002). Nutrição e exercício na prevenção e controle das doenças cardiovasculares. Revista Brasileira de Medicina do Esporte, 8, 244-254.

Ritchie, C.I.A. (1995). Comida e civilização. Lisboa: Assírio \& Alvim.

Rose, S. (2006). O cérebro do século XXI. São Paulo: Globo.

Sackheim, G.I., \& Lehman, D.D. (2001). Química e bioquímica para ciências biológicas. (8th edition). Barueri: Manole.

Sanders, T., \& Emery, P. (2003). Molecular basis of human nutrition. London: Taylor \& Francis.

Santos, H.S., \& Cruz, W.M.S. (2001). A terapia nutricional com vitaminas antioxidantes e o tratamento quimioterápico oncológico. Revista Brasileira de Cancerologia, 47, 303-308.

Schmidt-Nielsen, K. (1996). Fisiologia Animal (5th edition). São Paulo: Santos.

Shiva, V. (2003) Monoculturas da mente. São Paulo: Editora Gaia.

Soares, L.D., \& Petroski, E.L. (2003). Fatores etiológicos e tratamento da obesidade infantil. Revista Brasileira de Cineantropometria \& Desempenho Humano, 5(1), 63-74.

Somer, E. (2001). The origin diet: how eating like our stone age ancestors will maximize your health. New York: Henry Holt.

Speakman, J.R. (2006). Thrifty genes for obesity and metabolic syndrome: time to call off the search? Diabetes and Vascular Disease Research, 3(1), 7-11.

Stringer, C., \& Andrews, P. (2005). The complete world of human evolution. London: Thames \& Hudson.

Tomaselo, M. (2003). Origens culturais da aquisição do conhecimento. São Paulo: Martins Fontes.

Ungar, P.S. (2007). Evolution of the human diet: the known, the unknown, and the unknowable. Oxford: Oxford University Press.

Ungar, P.S., \& Teaford, M.F. (2002). Human diet: its origin and evolution. Westport: Bergin \& Garvey.

Wiell, A. (2001). A alimentação ideal para uma saúde perfeita. Rio de Janeiro: Rocco.

Willet, W.C. (2002). Coma, beba e seja saudável. Rio de Janeiro: Campus.

Wrangham, R. (2009). Pegando fogo: por que cozinhar nos tornou humano. Rio de Janeiro: Zahar.

Zucoloto, F.S. (2008). Por que comemos o que comemos? Rio de Janeiro: Editora Mauad. 